\title{
Approaches to Manual Ventilation
}

John D Davies MA RRT FAARC, Brian K Costa RRT, and Anthony J Asciutto RRT

\author{
Introduction \\ Evaluation of Spontaneous Ventilation \\ Causes of Inadequate Ventilation \\ Foreign Body Obstruction \\ Heimlich Maneuver \\ Airway Maneuvers \\ Optimal Head Position \\ Head Tilt/Chin Lift \\ Jaw Thrust \\ Cervical Spine Immobilization \\ Simple Airway Adjuncts \\ Oropharyngeal Airways \\ Nasopharyngeal Airways \\ Bag-Mask Ventilation \\ Difficult Mask Ventilation \\ MOANS \\ Incidence of Difficult Mask Ventilation \\ Summary
}

\begin{abstract}
Manual ventilation is a basic skill that involves airway assessment, maneuvers to open the airway, and application of simple and complex airway support devices and effective positive-pressure ventilation using a bag and mask. An important part of manual ventilation is recognizing its success and when it is difficult or impossible and a higher level of support is necessary to sustain life. Careful airway assessment will help clinicians identify what and when the next step needs to be taken. Often simple airway maneuvers such as the head tilt/chin lift and jaw thrust can achieve a patent airway. Appropriate use of airway adjuncts can further aid the clinician in situations in which airway maneuvers may not be sufficient. Bag-mask ventilation (BMV) plays a vital role in effective manual ventilation, improving both oxygenation and ventilation as well as buying time while preparations are made for endotracheal intubation. There are, however, situations in which BMV may be difficult or impossible. Anticipation and early recognition of these situations allows clinicians to quickly make adjustments to the method of BMV or to employ a more advanced intervention to avoid delays in establishing adequate oxygenation and ventilation. Key words: spontaneous ventilation; airway assessment; head position; head tilt/chin lift; jaw thrust; cervical spine immobilization; cricoid pressure; oropharyngeal airway; nasopharyngeal airway; bagmask ventilation; difficult mask ventilation. [Respir Care 2014;59(6):810-824. (C 2014 Daedalus Enterprises]
\end{abstract}

The authors are affiliated with Respiratory Care Services, Duke University Hospital, Durham, North Carolina.

Mr Davies serves on an advisory board for Philips Healthcare and is a clinical consultant for Teleflex Medical. Mr Costa and Mr Asciutto have disclosed no conflicts of interest.

Mr Davies presented a version of this paper at the 52nd ResPIRATORY CARE Journal Conference, "Adult Artificial Airways and
Airway Adjuncts," held June 14 and 15, 2013, in St Petersburg, Florida.

Correspondence: John D Davies MA RRT FAARC, Respiratory Care Services, Duke University Hospital, Box 3911 Duke North, Erwin Road, Durham, NC 27710. E-mail: john.davies@duke.edu.

DOI: $10.4187 /$ respcare. 03060 


\section{Introduction}

Management of the emergency airway is continually evolving, with a plethora of new devices continuously being developed. In the midst of these new technologies, the basics of airway management sometimes get overlooked. Things such as upper airway assessment, optimal head positioning, manual maneuvers to open the upper airway, use of simple airway adjuncts, and expert bagmask ventilation (BMV) are all basic, essential, and potentially life-saving respiratory therapy skills. In this paper, we discuss essential techniques involved in basic airway management.

\section{Evaluation of Spontaneous Ventilation}

A person experiencing inadequate gas exchange may require manual ventilation; however, often simple airway maneuvers to open the airway are sufficient to re-establish or improve spontaneous air movement. Although there are many causes of inadequate ventilation, they can be categorized into either central respiratory drive failure or peripheral airway obstruction. Airway obstruction can be further divided into the upper airway (mouth, nose, tongue, teeth, pharynx, etc) and lower airway (trachea, bronchi, alveoli, etc), with the larynx being the point of separation. The larynx is a special area of concern, as it is normally a narrow part of the gas conduction system and is often subjected to foreign body obstruction by aspiration of food. Complete foreign body obstruction is a life-threatening event that must be rapidly diagnosed and treated to prevent death.

Poor respiratory effort can be caused by intrinsic factors such as brain injury or extrinsic factors such as sedative (narcotic) drug overdose. Poor respiratory effort leading to inadequate ventilation is difficult to assess without advanced monitoring apparatus or blood gas analysis. However, through close observation of the respiratory pattern, the clinician often can discern ineffective respiratory efforts. Breathing frequency, depth of respiration (chest rise), breathing pattern (regular vs irregular), and use of accessory muscles can all be clues to the presence and cause of inadequate ventilation.

\section{Causes of Inadequate Ventilation}

Central respiratory failure can manifest itself in several different ways. A patient with a neurologic injury will likely have a rapid breathing frequency with low tidal volumes $\left(\mathrm{V}_{\mathrm{T}}\right)$. The patient with a spinal cord injury will exhibit diaphragmatic breathing usually with the use of accessory muscles. A drug overdose patient will breathe with a very slow rate and large $\mathrm{V}_{\mathrm{T}}$. It is important to note that any or all of the breathing patterns can result in significant hypoventilation. In these cases, simple airway maneuvers will ensure a patent airway but will not correct the underlying hypoventilation problem. Additional measures (discussed below) will be required to maintain adequate ventilation. Altered mental status is often a precursor to progressive respiratory failure. In all cases, preparations should be made to provide endotracheal intubation, as respiratory compromise may occur suddenly.

\section{Foreign Body Obstruction}

Airway obstruction can be caused by the patient's own soft tissue (ie, large tongue, tongue or upper airway edema, injured tissue, blood, or secretions) or by a laryngeal foreign body or vocal cord edema. Airway obstruction from a patient's own tissue is often relieved by simple head positioning. Laryngeal foreign body obstruction usually presents a more dangerous problem. Signs of inadequate ventilation stemming from laryngeal foreign body airway obstruction are usually more obvious than depressed respiratory effort. Obstruction may be partial or complete. Mild airway obstruction is usually characterized by adequate air exchange with wheezing or gurgling sounds. If an effective cough is present, the clinician should not interfere with the patient's attempts to expel the foreign body. In this case, continued observation may be all that is needed. If the patient is unable to expel the foreign body and remains frantic, then the emergency response system should be activated.

\section{Heimlich Maneuver}

Severe airway obstruction is characterized by very poor or absent air exchange accompanied by a weak ineffective cough or no cough at all. The patient is unable to speak and will show signs of increased respiratory difficulty, and cyanosis may be present. A classic indication that a patient has severe airway obstruction is the universal choking sign (clutching the neck with both hands). At this point, intervention should be attempted to relieve the obstruction. The Heimlich maneuver (also referred to as chest or abdominal thrusts) was first described in 1974 and has long been accepted as a method to help expel a foreign body. ${ }^{1}$ It is performed by standing or kneeling behind the patient in the following manner: (1) making a fist with one hand and placing the thumb side of the fist against the abdomen above the navel but below the sternum, (2) grasping the fist with the other hand, and (3) making a quick upward thrust. This should be repeated until the foreign body is expelled or speech returns. In pregnant or obese individuals, abdominal thrusts will most likely not be effective. In these scenarios, it may be more effective to use chest 
thrusts. This technique involves placing the clasped hands on the center of the chest, on the lower part of the sternum, and applying quick downward movements.

If the patient becomes unconscious, lay him down on the ground, and begin cardiopulmonary resuscitation. Every time the airway is opened to deliver rescue breaths, a quick visual inspection should be done to see if the obstructing object has become visible. If so, it may be removed and rescue breathing continued until the patient makes his own spontaneous efforts. If the object is not visible, blind finger sweeps can actually do harm by pushing the object farther down into the airway, creating a more severe obstruction that will be more difficult to dislodge. If the individual is conscious and no one else is present, the Heimlich maneuver has been successfully performed by the victim himself. This has been accomplished by using a fixed object such as a railing or table edge and applying a quick jolt of pressure into the abdomen. There are even self-assist emergency choking devices available on the market. These devices are designed to make it easier to perform abdominal thrusts by the victim themselves. In choking infants, relief of a foreign body obstruction is performed through the use of a series of alternating chest thrusts and back blows.

Although the Heimlich maneuver is accepted practice for the relief of choking victims, the procedure is not without potential complications. Excessive pressure or inappropriate application of abdominal thrusts can lead to rib or xiphoid fractures as well as internal damage from the xiphoid process. ${ }^{2}$ Other rare complications have been seen, the most common of which is rupture of the stomach, the esophagus, and the jejunum..$^{3-10}$ This usually occurs in patients who have consumed large quantities of food leading to gastric distention. There are also reports of other rare traumatic complications of the Heimlich maneuver, including pneumomediastinum, diaphragmatic herniation, and mesenteric/splenic laceration. ${ }^{11-14}$ Most of these reports involve elderly patients.

Anticipating and planning for potential problems are fundamental to airway management. Failure to do so, particularly when a simple physical exam might have predicted a difficult airway, can have devastating consequences. The presence of pathologic factors or a combination of issues may provide early indicators of potential difficulty with BMV and/or endotracheal intubation. These are discussed in detail in other papers in this issue of Respiratory CARE. Poor outcomes may be avoided by implementing a comprehensive approach that starts with a thorough airway assessment and includes providing appropriate care. After recognizing inadequate ventilation, the first step should be making sure that the airway is open. ${ }^{15}$

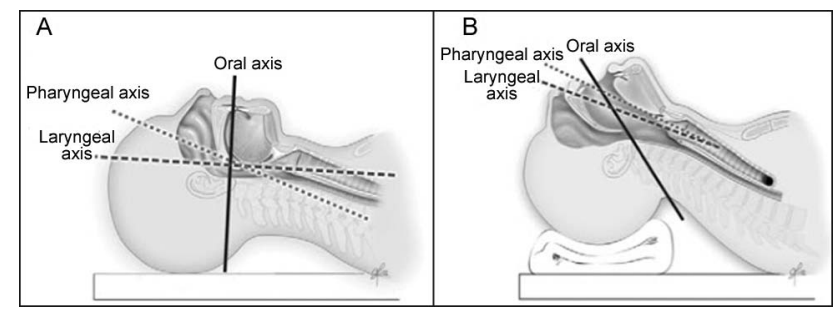

Fig. 1. A: Supine position and B: the sniffing position. From Reference 15 , with permission.

\section{Airway Maneuvers}

\section{Optimal Head Position}

The ideal head position should line up and open the airway passages leading into the lungs. Optimal head positioning alone may provide a patent airway in the majority of patients requiring airway support. However, minor changes in head and neck positioning during airway management may alter the airway patency significantly. When airway patency is essential, these issues become critically important as BMV is provided. Soft tissue upper airway obstruction can often be managed by using manual techniques; CPAP and BMV may not be needed. The most commonly used techniques to achieve optimal head position and maintain a patent airway include the sniffing position and the head-tilt/chin-lift and jaw-thrust maneuvers.

The sniffing position has traditionally been recommended as the best head position to facilitate effective airway management in patients who are not at risk of cervical spine injury. The sniffing position is achieved by elevating the head $\left(15^{\circ}\right)$ and extending it on the neck $\left(35^{\circ}\right)$ of a patient in the supine position (Fig. 1). Its main advantage is to provide optimal exposure of the glottis by aligning the oral, pharyngeal, and laryngeal axes. However, the effectiveness of the sniffing position over other airway maneuvers has not been clearly established to help with BMV.16,17 Although the classic sniffing position has been widely accepted by clinicians dating back to the early 20th century, its efficacy has even been questioned in optimizing glottic exposure during intubation, especially in obese patients. ${ }^{18}$ Some authorities have questioned use of the sniffing position even in patients considered to be of normal size or who have a normal airway. ${ }^{19-22}$ Despite this controversy, the sniffing position is still generally accepted as the best starting position in airway management. ${ }^{2}$

\section{Head Tilt/Chin Lift}

The head tilt/chin lift is one of the most common active maneuvers used to open a patient's airway. This maneuver should be used only if the clinician is confident that there is no risk of cervical spine injury. Standing on the side of 


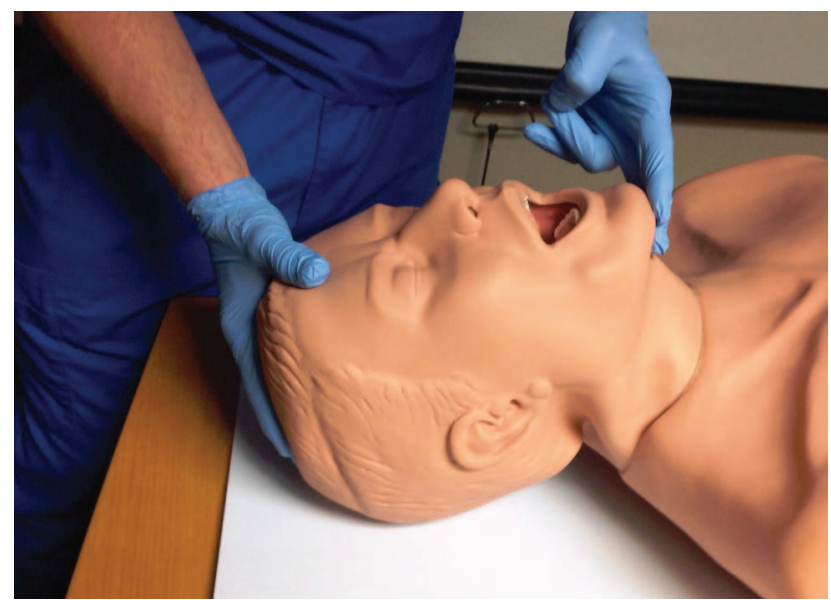

Fig. 2. Head tilt/jaw lift.

the patient, the clinician places one hand on the patient's forehead while simultaneously placing the fingers of the other hand under the patient's mandible. The head is then tilted backward while lifting the mandible forward, extending the neck (Fig. 2). This action creates an open airway by lifting the tongue from the posterior pharynx. If effectively applied, the head-tilt/chin-lift maneuver may allow the patient to resume unobstructed breathing without further intervention. Compared with the sniffing position, the head tilt/chin lift appears to offer similar advantages in most patients. However, the sniffing position appears to be advantageous in patients with limited head extension. ${ }^{23}$

\section{Jaw Thrust}

The jaw thrust is preferred over the above mentioned techniques in known or suspected cases of cervical spine injuries because the head and neck remain in a more neutral position when it is applied. When performing a jawthrust maneuver, the clinician stands behind the head of the patient, places the fingers of both hands on the left and right sides under the angles of the mandible, and applies forward and upward pressure (Fig. 3). As with the head tilt/chin lift, the jaw-thrust maneuver displaces the tongue from the posterior pharynx, but does so while keeping the patient's head and neck in a neutral position, and may allow the patient to resume unobstructed breathing without further intervention. A modified jaw thrust may even be safer for patients with suspected cervical spine injury. This maneuver involves anteriorly displacing the jaw without movement of the head.

\section{Cervical Spine Immobilization}

Most manual airway maneuvers are associated with some movement of the cervical spine. It has been estimated that

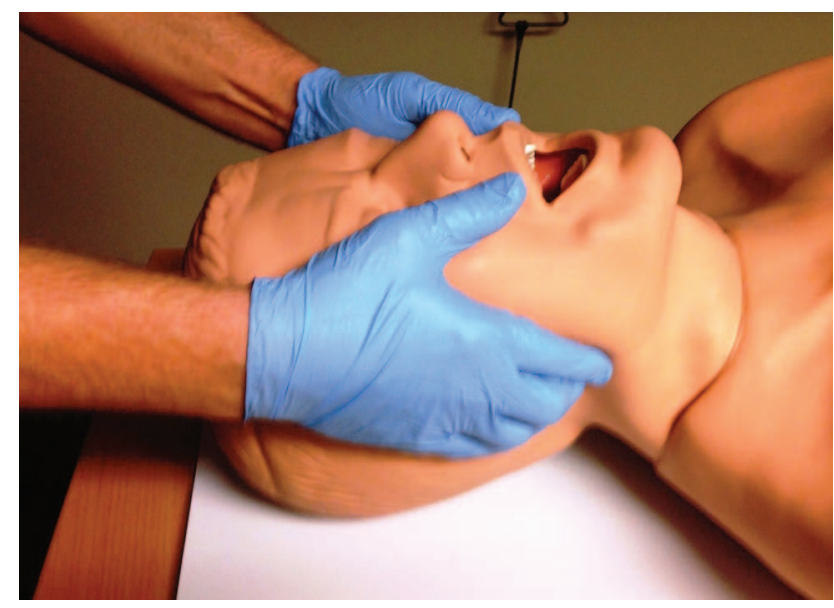

Fig. 3. Jaw thrust.

$\sim 2 \%$ of all victims of blunt trauma have a spinal cord injury; this risk increases 3 -fold if the patient has a craniofacial injury. ${ }^{24}$ In a patient with a known or suspected cervical spine injury, regardless of the maneuver used, the clinician must minimize head and neck movement. Failure to do so can cause significant and permanent neurologic injury to the patient. There are 2 generally accepted techniques to minimize cervical spine movement: the cervical collar (Fig. 4A) and manual in-line stabilization (Fig. 4B). If adequate personnel are available, manual in-line stabilization is preferred over cervical collars for maintaining cervical spine stability. Although cervical collars are designed to restrict movement of the neck, they have the potential to still allow movement and interfere with airway management. ${ }^{22,25}$ If manual in-line stabilization is continuously maintained, clinicians may safely remove the front half of the cervical collar to provide basic as well as advanced airway management.

\section{Cricoid Pressure}

During airway maneuvers and BMV, the patient is at risk of aspiration of regurgitated gastric contents. Aspiration risk increases if the patient is unconscious or has no airway-protective reflexes. Attempts to prevent regurgitation and aspiration include placing the patient with a $30^{\circ}$ head-up tilt or with the head placed lower than the body and the mouth rotated to the side so that vomited material drains out of the pharynx and not into the lung. These positions are generally not convenient during active airway support, and other techniques are suggested to prevent aspiration. The use of cricoid pressure (backward pressure of the cricoid cartilage toward the esophagus) can minimize the passage of air into the stomach and help prevent regurgitation from gastric distention in an unconscious patient. ${ }^{23}$ This maneuver was first described in 1961 by BA 

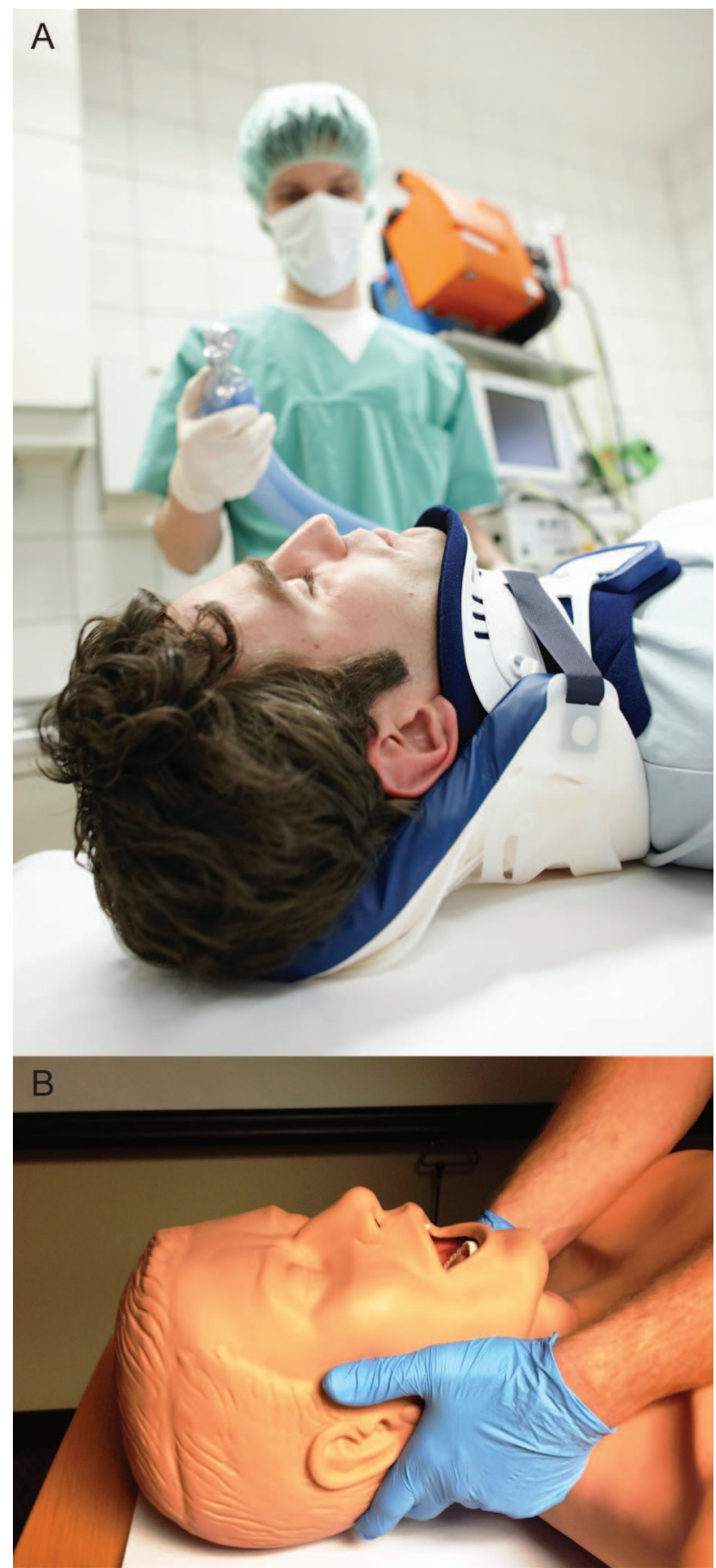

Fig. 4. A: The Occian Back cervical collar. Courtesy Össur Inc. B: Manual cervical spine immobilization.

Sellick as a method to reduce the likelihood of gastric and esophageal regurgitation during anesthesia induction. ${ }^{26}$ The term Sellick maneuver and cricoid pressure are often used interchangeably by airway management personnel. Cricoid pressure may be beneficial in aligning the airway passages during BMV as well as improving laryngoscopic view during intubation. Cricoid pressure is accomplished by the clinician placing his thumb and index or long finger on each side of the cricoid cartilage and applying posterior pressure to occlude the esophagus against the vertebral column. Even if properly applied, cricoid pressure can have the reverse effect of interfering with airway management and making ventilation and intubation more difficult. ${ }^{27,28}$ Training in the proper technique of cricoid pressure usually is not done formally (through structured courses) and is often accomplished when needed urgently at the bedside. Even among anesthesia providers, there is a lack of training in properly performing and applying cricoid pressure. ${ }^{29}$ In one study, researchers found that $48 \%$ of participants without significant previous training applied cricoid pressure improperly. ${ }^{30}$ However, the same group showed that, with proper guidance and practice, the correct amount of force can be delivered in a consistent manner. ${ }^{30}$

\section{Simple Airway Adjuncts}

Maintaining a patient's airway is of vital importance after it has been established by manual means, and airway adjuncts (oropharyngeal and nasopharyngeal airways) are important tools in achieving this goal. These devices are useful in patients with airway obstruction or those at risk for developing airway obstruction. Once a patent airway is established, it is necessary to prevent it from becoming obstructed again. Oral and nasopharyngeal airways may be useful to improve ventilation, particularly when oropharyngeal structures, such as the tongue, are obstructing the airway. To achieve this, the practitioner may use either or both adjuncts.

\section{Oropharyngeal Airways}

Oropharyngeal airways (OPAs) may aid in the delivery of adequate ventilation during BMV by physically preventing the tongue from occluding the airway. This adjunct should be used only in patients who are unresponsive or unconscious and who have no gag reflex or cough. In responsive or alert patients, pharynx stimulation by the OPA can induce vomiting and make aspiration more likely.

OPAs come in various sizes and are designed to be inserted into the mouth between the lips and teeth (Fig. 5). Selection of the appropriate size airway and proper placement are necessary to ensure that the adjunct is used in a safe and effective manner. To ensure proper size, the clinician should place the airway against the side of the patient's face with the flange at the corner of the mouth. The tip of an appropriately sized OPA should just reach the angle of the patient's mandible (Fig. 6). An OPA that is too short is worse than one that is too long. An OPA that is too short will actually push the tongue back farther in the airway and make the obstruction complete. 


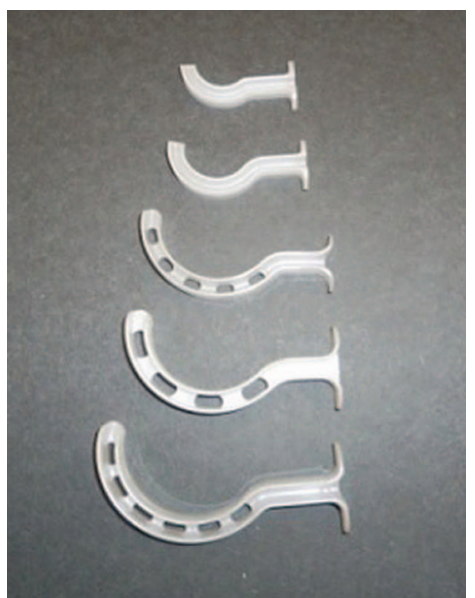

Fig. 5. Different sizes of oropharyngeal airways.

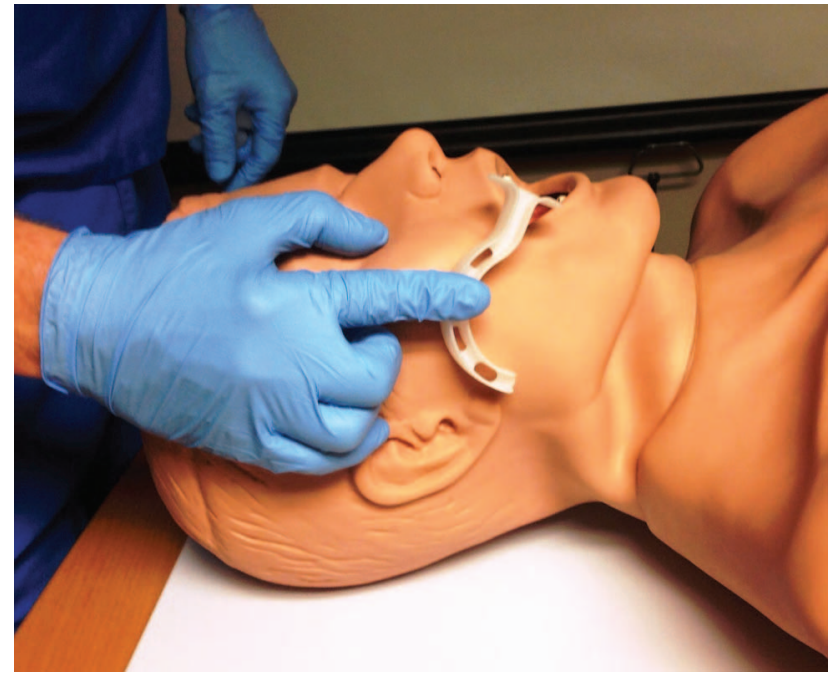

Fig. 6. Choosing the correct size of oropharyngeal airway.

Proper placement of this device is critical, and care must be taken not to displace the tongue into the posterior pharynx and occlude the airway. Insertion of an OPA may be accomplished by a variety of methods. One method is to start with the curve of the adjunct inverted (opposite of its resting position) and advance the tip along the palate until it reaches the posterior pharynx past the tongue. At this juncture, the device is then rotated $180^{\circ}$ (back to the resting position), ensuring that its tip is behind the base of the tongue (Fig. 7). Another method is to use a tongue blade to navigate past the tongue. It allows for the tongue to be displaced as the adjunct is advanced, with it aligned to the final resting position. The OPA can be inserted at a $90^{\circ}$ angle from the side of the mouth using the device as a form of tongue blade and then rotating it back $90^{\circ}$ into position after the tongue is past. Lastly, a 2-hand jaw thrust can be employed while inserting an OPA to push the protruding airway up to the teeth to help seat the airway.

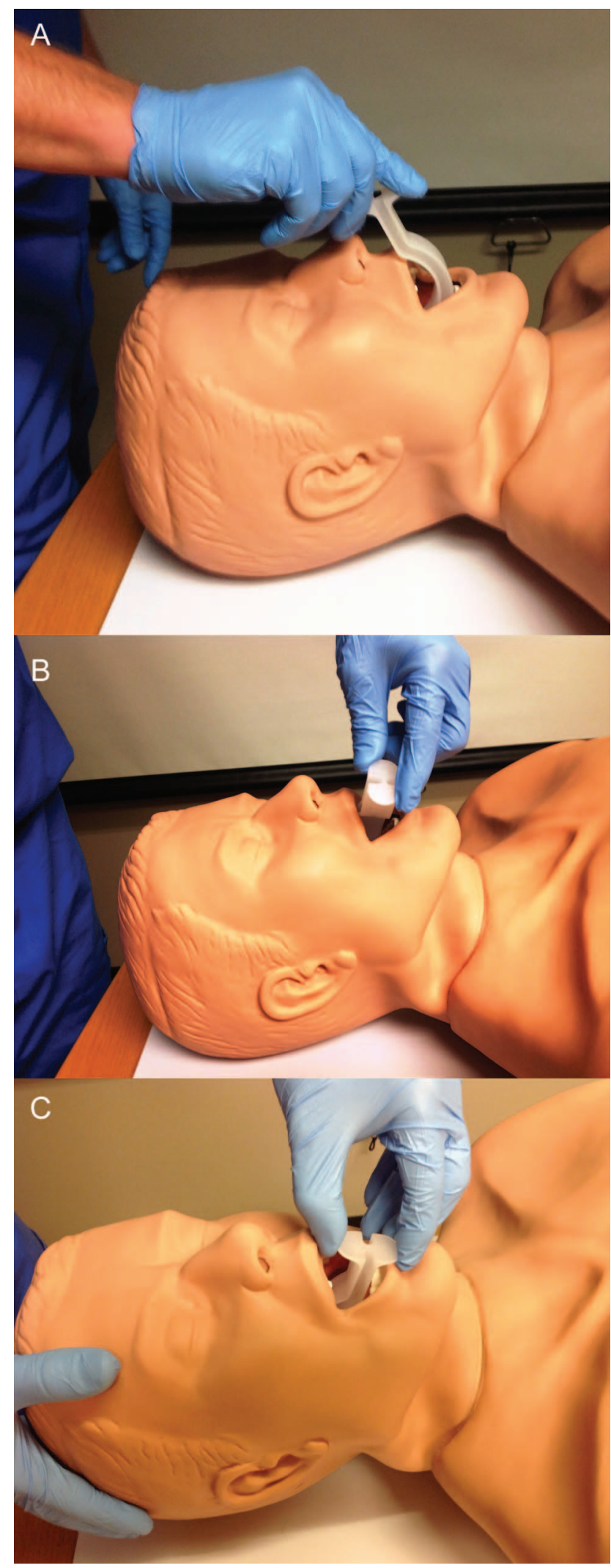

Fig. 7. Insertion of an oropharyngeal airway. 
Whichever method is chosen, after inserting the OPA, assess the patient for airway patency by observing chest movement during spontaneous or assisted (BMV) breaths. In addition to the increased risk for vomiting and aspiration when used on an awake responsive patient, complications of OPAs include dental damage (due to broken teeth during insertion or misplacement of various dental implants), damage to the lips and tongue (due to pinching by and chewing of the device), and pressure ulcer formation with prolonged use.

\section{Nasopharyngeal Airways}

The nasopharyngeal airway (NPA) is another device that can be used to provide relief of upper airway obstruction, by itself or in concert with an OPA. As with OPAs, NPAs come in a variety of sizes (Fig. 8), and choosing the correct one depends on the individual patient's anatomy. The NPA is a simple airway adjunct used by a number of health care disciplines. NPAs have advantages over OPAs in that they can be used in patients with an intact gag reflex, trismus, or oral trauma and are better tolerated than oral airways in patients who are not deeply unconscious. ${ }^{31,32}$ A properly sized NPA is based on its length rather than diameter, although the size and shape of the nasal passage will limit the size than can be used. The correct device can be determined by placing the flange at the tip of the patient's nose and the beveled angle of the airway at the meatus of the ear or the angle of the mandible (Fig. 9). This will ensure that the NPA is of adequate length to lie beyond the tongue. If too short, the airway would fail to separate the soft palate from the posterior wall of the pharynx, and if too long, it may enter the larynx and trigger laryngeal reflexes. It may enter the space between the epiglottis and the tongue (vallecula), where the airway could become obstructed. Safe placement of the NPA requires the device to be well lubricated with a water-soluble jelly. The NPA is then inserted into the naris and advanced into the posterior pharynx. To avoid trauma, the NPA should be inserted directly backward and not up the nose, with constant slow pressure. Decongestants may be helpful if administered before insertion is attempted. If resistance is met, the tube can be slightly rotated and then re-advanced. NPAs come in different textures, and the softer ones, while more prone to collapse, are less likely to cause bleeding. A pediatric uncuffed endotracheal tube cut to the correct length may also be used as an NPA in adults.

Complications associated with the use of NPAs include failure of insertion, epistaxis (due to mucosal tears or avulsion of the turbinates), laryngospasm, submucosal tunneling, and pressure sores. Contraindications include nasal airway occlusion, nasal fractures, coagulopathy (risk of epistaxis), cerebrospinal fluid rhinorrhea (resulting from

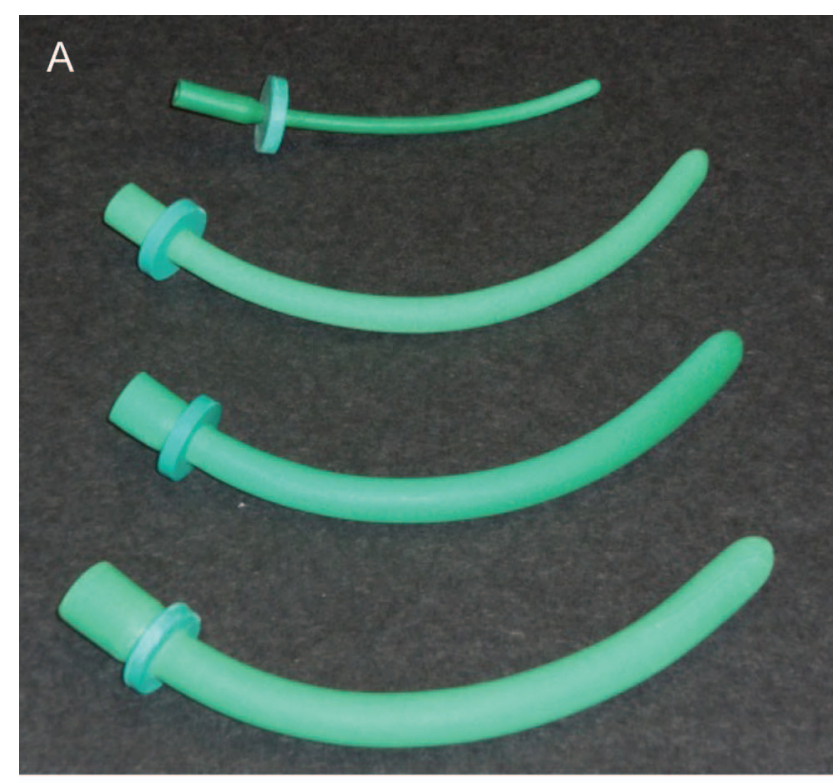

B

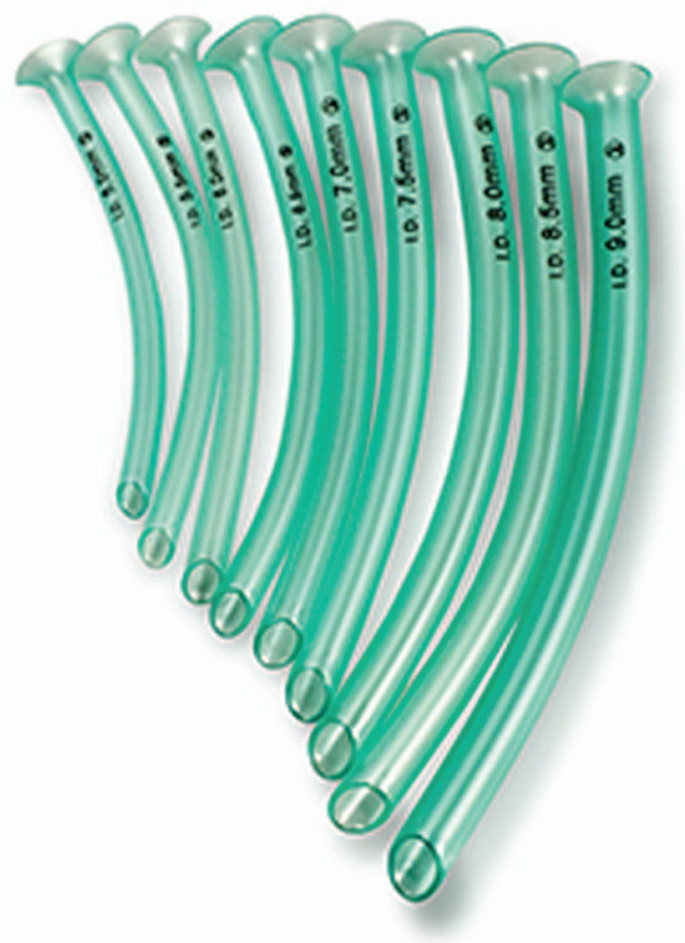

Fig. 8. Different sizes of nasopharyngeal airways. Image B courtesy of Dynarex Inc.

base skull fracture), and adenoid hypertrophy (in pediatric patients). ${ }^{33}$

\section{Bag-Mask Ventilation}

BMV is the cornerstone of basic airway management and is not a skill easily mastered. Effective BMV requires proper mask selection, effective hand placement, and co- 

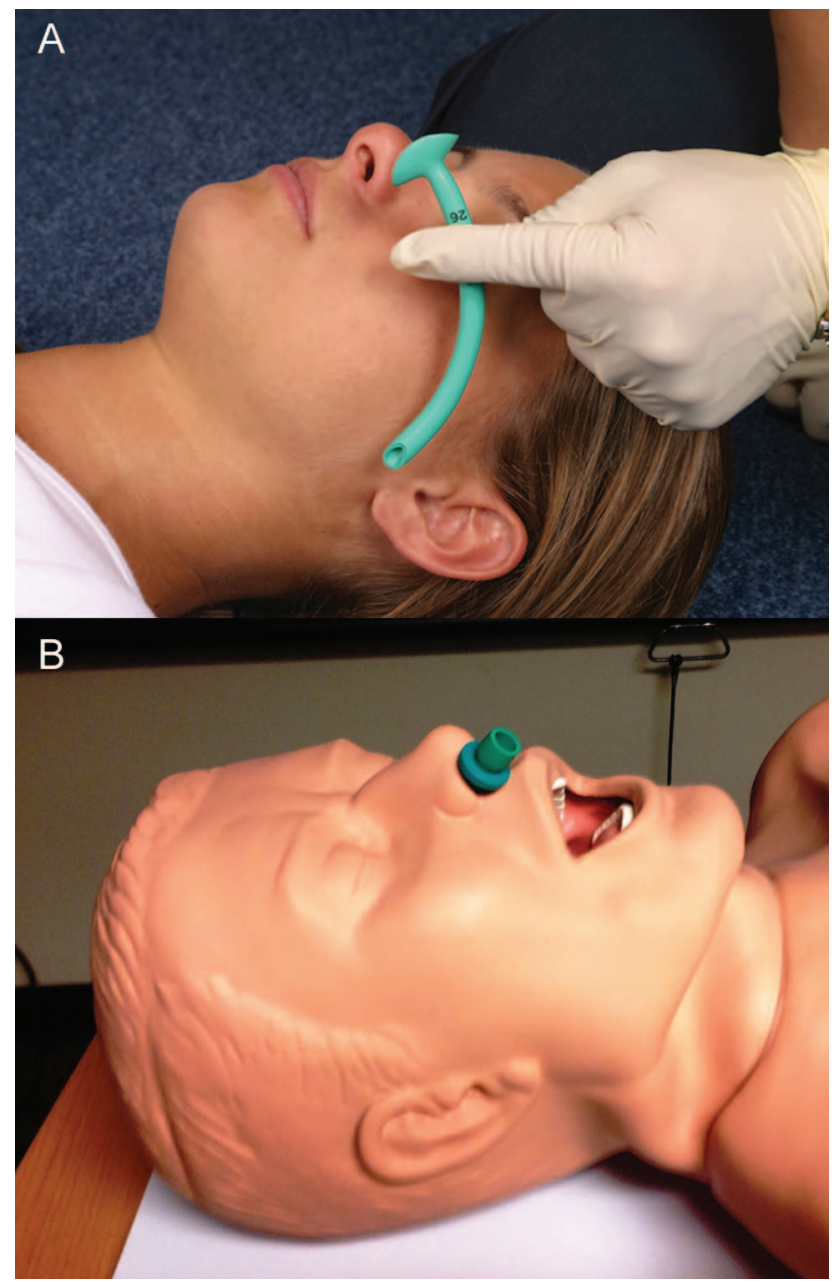

Fig. 9. Choosing the correct size of nasopharyngeal airway. Image A from Reference 50, with permission.

ordinated manual compression of the ventilation bag. Successful BMV requires a patent airway being present, an adequate seal of the mask on the face, and appropriate ventilation pressures.

There are 2 types of manual ventilation devices: the flow-inflating (non-self-inflating) bag and the self-inflating bag. The flow-inflating bag requires a continuous flow of gas from an external gas source. Pressure is controlled by the flow setting and the pressure-release valve. These bags are capable of delivering both CPAP and PEEP. The flow-inflating bags are used mainly in the neonatal population and in the operating room during anesthesia induction prior to intubation. The self-inflating bag consists of an air-intake valve, a non-rebreathing valve, an oxygen inlet nipple, and an oxygen reservoir (either a corrugated tubing reservoir or a bag reservoir). These types of bags also incorporate a pressure-release valve to prevent excessive pressure buildup. PEEP can also be obtained using an external valve. However, in some instances, such as secretion buildup, PEEP valves may add resistance to exha-

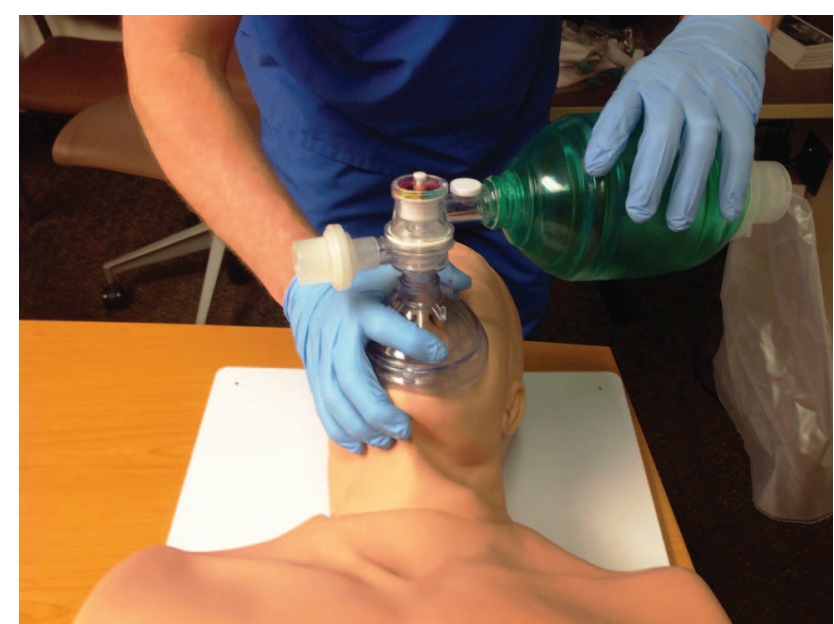

Fig. 10. One-clinician single-hand mask seal for bag-mask ventilation.

lation. When the bag is compressed, the non-rebreathing valve directs gas from the bag to the patient. As pressure on the bag is released, patient-exhaled gas is directed through a valve while the bag automatically re-inflates with oxygen-enriched gas from the reservoir.

Although self-inflating bags are able to fill without an external gas source (ie, with room air), they are usually used with an external oxygen source. These types of bags are in almost all hospital settings involving pediatric and adult patients to be used for emergency airway events.

To initiate BMV, one must first select an age-appropriate mask. The mask is then placed on the patient's face, with the nasal portion at the bridge of the nose. Three facial landmarks that need to be covered for effective ventilation are the bridge of the nose, the 2 malar eminences, and the mandibular alveolar ridge. The 2 accepted methods for effective mask seal during BMV are the one-person single-hand technique and the 2-person 2-hand method. To perform the single-hand technique, the middle, ring, and little fingers are placed on the mandible, bringing it up toward the mask in a chin-lift fashion. The soft tissue between the thumb and index finger is placed against the bag-mask connector and is used to provide sufficient even pressure on the face to obtain a seal (Fig. 10). Periodically alternating left and right hands can be used to prevent mask leaks and ventilation failure from fatigue.

The 2-hand technique requires the services of 2 clinicians and is considered the most effective BMV method in the unintubated patient (children and adults). ${ }^{34,35}$ One clinician provides the ventilation, while the second clinician is responsible for the placement of the mask and creation of an adequate seal. For correct positioning, the second clinician places both thumbs and index fingers on the inferior and superior ridges of the mask. The remaining 3 


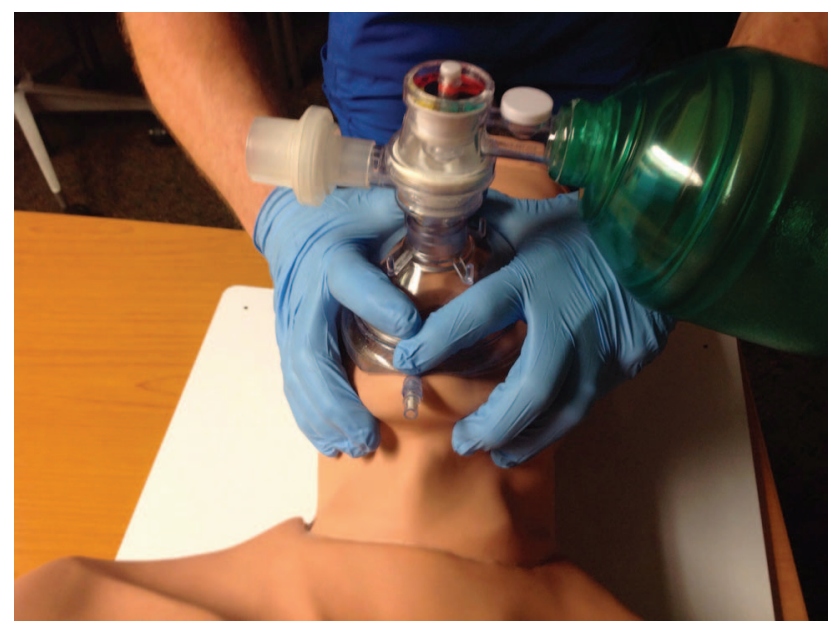

Fig. 11. The 2-hand mask seal for bag-mask ventilation.

fingers on each hand are used to lift the mandible much in the same way as with the one-person technique (Fig. 11). While experienced clinicians might provide adequate BMV by themselves, the 2-hand technique is usually more effective and recommended if adequate personnel are available. Obtaining an adequate seal in large patients can be challenging even with the 2-person method of BMV. Excessive tissue makes it very difficult to maintain the alignment and seal with the single-person technique. Beards create similar problems in achieving an adequate seal. Edentulous patients can also pose difficulties in BMV due to lack of support of the facial soft tissues and distortion leading to an inadequate seal. Learning effective BMV requires continual practice and instruction under the guidance of an experienced clinician. It is not clear what the minimum amount of training for BMV is. Komatsu et $\mathrm{al}^{36}$ examined a group of interns and determined that it takes between 25 and 30 attempts to be considered effective at BMV.

Care must be taken to provide appropriate $\mathrm{V}_{\mathrm{T}}$ during BMV. Excessive volume or pressure can lead to increased air entering the stomach, causing gastric distention and increasing the chance of regurgitation and aspiration. Cricoid pressure during BMV can potentially help reduce the amount of air being forced into the stomach and lower the likelihood of regurgitation. ${ }^{37}$ Gastric inflation can also potentiate diaphragmatic elevation and reduce respiratory compliance. ${ }^{32} \mathrm{~A} \mathrm{~V}_{\mathrm{T}}$ between 500 and $600 \mathrm{~mL}$ is considered reasonable to avoid significant stomach inflation in an unintubated patient. ${ }^{32,38}$ Since BMV devices have no direct measure of delivered volume, it can be difficult for inexperienced personnel to estimate ventilation efficacy. Only through experience can clinicians achieve appropriate $\mathrm{V}_{\mathrm{T}}$ that limits gastric inflation as well as provides lung-protective ventilation during prolonged BMV. The risks of inadvertent high-pressure ventilation may be re- duced by using a manometer attached to a resuscitation bag.

Monitoring of the patient receiving BMV includes clinical assessment, pulse oximetry $\left(\mathrm{S}_{\mathrm{pO}_{2}}\right), \mathrm{CO}_{2}$ monitoring, transcutaneous blood gas monitoring, and arterial blood gas (ABG) analysis. Clinical assessment in BMV is important to determine its effectiveness and prevent complications. Things such as chest excursion, ease of bagging, and skin color can all aid the clinician in BMV evaluation. Lack of chest excursion or difficulty in bagging should alert the clinician to reposition the head and/or mask to increase the effectiveness of BMV.

$\mathrm{S}_{\mathrm{pO}_{2}}$ can be used to quantitate the arterial oxyhemoglobin saturation during BMV. $\mathrm{S}_{\mathrm{pO}_{2}}$ can also be used to minimize the effects of hyperoxia on lung alveolar cells. Instead of targeting a maximal $\mathrm{S}_{\mathrm{pO}_{2}}$, the clinician can target a clinically effective but safe $\mathrm{S}_{\mathrm{pO}_{2}}$. Pulse oximetry is very safe, but it is important to keep in mind that device limitations may yield false-negative (hypoxemia) or false-positive (normoxia or hyperoxia) results. Factors that can affect the performance of a pulse oximeter include motion artifact, abnormal hemoglobins, low-perfusion states, skin pigmentation, or nail polish (with finger probes). Ideally, the $\mathrm{S}_{\mathrm{pO}_{2}}$ reading should be compared with arterial oxygen saturation (if an ABG result is available) to establish agreement. Pulse oximetry is used widely throughout the hospital setting but is most commonly used in the ICU to assess oxygenation during mechanical ventilation and in step-down areas, where respiratory compromise is a greater possibility than on the general wards. Remote monitoring of $\mathrm{S}_{\mathrm{pO}_{2}}$ is often done in these setting as well for earlier detection of problems. $\mathrm{CO}_{2}$ monitoring is desirable in instances in which inadequate ventilation is a possibility. The detection of hypercarbia can alert clinicians to impending respiratory failure. While capnometry is used mainly in conjunction with an endotracheal tube, some specially equipped oxygen delivery devices (nasal cannulas, oxygen masks) can be used to assess ventilation.

Transcutaneous blood gas monitoring uses measurements at the skin's surface to provide estimates of $\mathrm{P}_{\mathrm{aO}_{2}}$ and $\mathrm{P}_{\mathrm{aCO}_{2}}$. This technique is usually more accurate in the neonatal and pediatric populations, where it is therefore primarily used, although transcutaneous $\mathrm{P}_{\mathrm{aCO}_{2}}$ monitoring is increasingly used with adults. Transcutaneous measurements are also subject to false-negative and false-positive results, which may lead to inappropriate treatment. If possible, the results should be compared with an $\mathrm{ABG}$, if available. ABG analysis gives the most detailed and accurate reflection of the effectiveness of both oxygenation and ventilation. However, ABGs are more invasive (unless an arterial line is present) and may be difficult to obtain in low-perfusion states. 
Table 1. Definitions of Difficult Mask Ventilation

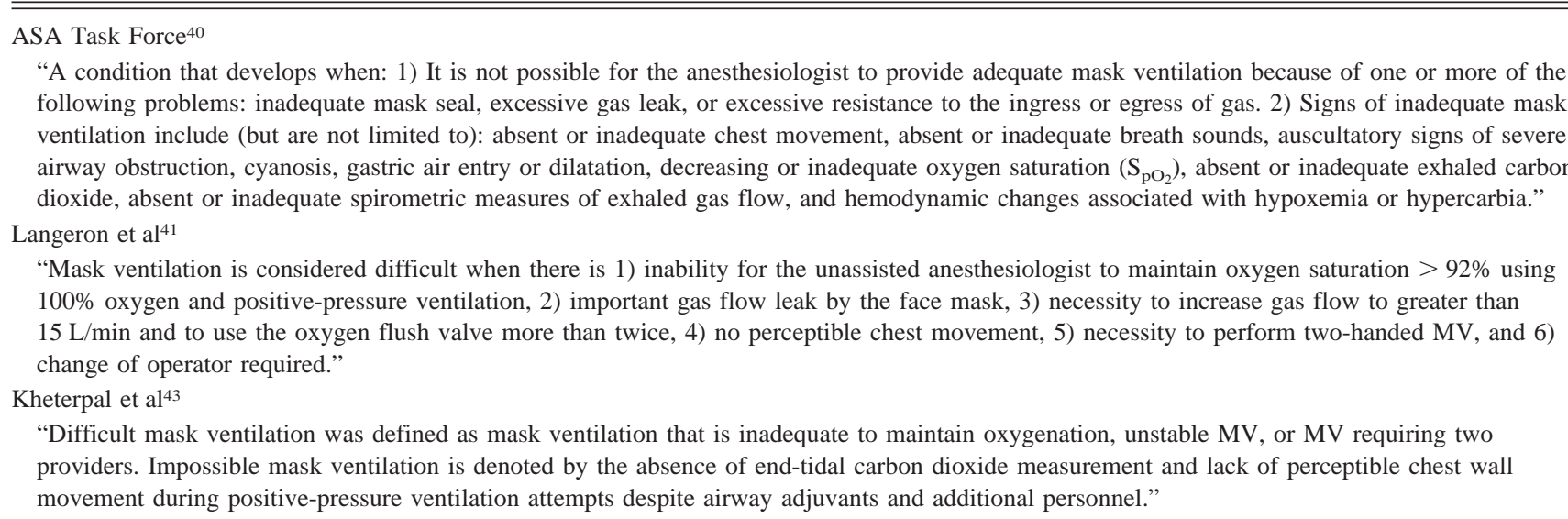

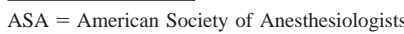

$\mathrm{MV}=$ mask ventilation

\section{Difficult Mask Ventilation}

Although all airway skills are important, probably the most important skill is the ability to effectively ventilate and oxygenate a patient with BMV. There is very little science published on how to predict ventilation failure and how best to respond to the situation of a patient found to be difficult to ventilate with conventional devices. Experts agree that more knowledge and understanding of how to handle this situation are needed. ${ }^{23,39}$ Difficult mask ventilation (DMV) is a real phenomenon that unfortunately has been sparsely studied. Part of the reason is that there is no agreed upon standard definition of DMV. The subjective and operator-dependent nature of the ability to perform effective mask ventilation makes it difficult to establish a specific event to be studied. However, DMV has not been without some study. There have been several attempts to define DMV. ${ }^{40-42}$ Most of these definitions stem from operating room-related anesthesiology experience. Perhaps the most general definition comes from Yildiz et $\mathrm{al}^{42}$ : "Difficult mask ventilation develops when there are signs of inadequate ventilation evidenced by no perceptible chest movement, oxygen desaturation, and perception of severe gas leak around the mask." Other suggested definitions are depicted in Table $1 .{ }^{40,41,43}$ Attempts have been made to develop a numerical scale for grading BMV similar to grading scales for laryngeal views. One such example is from Han et al (Table 2). ${ }^{44}$ The scale includes 5 grades, from grade 0 , with no requirement for BMV, to grade 4, with inability to ventilate. ${ }^{44}$ Unfortunately, this type of interpretation is fairly subjective and clinician-dependent.

DMV can be the result of many factors but generally falls into one of 3 categories: technique, upper airway anatomy, and lower airway disorders. Technique-related
Table 2. Classification of Difficult Mask Ventilation

\begin{tabular}{ll}
\hline \hline Classification & \multicolumn{1}{c}{ Description/Definition } \\
\hline Grade 0 & Ventilation by mask not attempted \\
Grade 1 & Ventilated by mask \\
Grade 2 & Ventilated by mask with oral airway or other adjuvant \\
Grade 3 & Difficult mask ventilation (inadequate, unstable \\
& requiring 2 practitioners) \\
Grade 4 & Unable to mask ventilate \\
& \\
\hline Adapted from Han et al. ${ }^{44}$ \\
\hline
\end{tabular}

causes of DMV include lack of clinician experience and/or inappropriate or faulty equipment. Perhaps the most important is the level of clinician experience. BMV competence should be achieved through formal training and experience. An inexperienced clinician could lack the techniques to achieve a proper seal in the face of abnormal anatomy. Improper head position and improperly applied cricoid pressure can hamper effective ventilation as well. ${ }^{28,45}$ Equipment factors include improper mask size, improper OPA or NPA, and a faulty resuscitation bag. Upper airway factors that contribute to DMV impede airflow delivery and include things such as tongue or epiglottis swelling, excessive soft tissue (morbid obesity and sleep apnea), tumors, foreign bodies, airway edema (eg, repeated intubation attempts, angioedema), and laryngospasm. Lower airway obstruction, although not as contributory as upper airway obstruction, can affect BMV. Severe asthma can prevent effective BMV. It is important to consider a differential diagnosis when managing a DMV situation to identify and rectify any correctable causes. 


\section{MOANS}

The mnemonic MOANS can be useful in rapidly assessing patients who may be difficult to bag-mask ventilate so that the appropriate measures to avoid a failed airway can be taken:

- M for Mask Seal: This refers to factors that make for a difficult mask seal, such as beards, blood, nasogastric tubes, and facial injuries/abnormalities. The presence of a beard has been identified as an easily modifiable risk factor for a difficult mask seal. ${ }^{41,43}$

- O for Obesity/Obstruction: Obese patients are inherently more difficult to bag-mask ventilate, as are third-trimester women due to their increased body mass. ${ }^{41,46}$ Higher pressures are required to overcome the reduced compliance to achieve an effective $\mathrm{V}_{\mathrm{T}}$. The obese patient also has redundant tissues in the supraglottic airway, leading to increases in airway resistance. The use of a PEEP valve in conjunction with BMV may help in ventilating this type of patient. Elevating the head (reverse Trendelenburg) may reduce impedance to air flow from the weight of the abdomen. Two-person BMV should be used in general and in particular with obese patients to achieve adequate oxygenation and ventilation. Upper airway abscesses, angioedema, epiglottitis, hematomas, cancers, and foreign bodies should alert the clinician to a possible airway obstruction and represent warning signs for difficulty in BMV.

- A for Aged: Patients older than 55 y are likely to experience more difficultly in BMV due to a loss of muscle tone in the upper airway decreasing patency. These patients may have a history of snoring and/or obstructive sleep apnea.

- $\mathrm{N}$ for No Teeth: Edentulous patients or patients with dentures may lack the necessary structural support for an effective mask seal during BMV.

- S for Stiff Lungs: Patients with any condition that increases pulmonary resistance or with decreased compliance may prove difficult to bag-mask ventilate. This need for additional ventilatory support leads to difficulty in maintaining an effective mask seal. Patients with exacerbations of asthma or COPD, as well as patients with ARDS, pulmonary edema, and advanced cases of pneumonia, are typically at risk for DMV.

Other tools that may help clinicians predict DMV include the mandibular protrusion test and the use of the Mallampati classification system. The mandibular protrusion test represents the ability of the patient to protrude the lower jaw in front of the upper jaw. ${ }^{47,48}$ This test categorizes patients into one of 3 classifications depending on how far they can protrude their lower incisors: class A, the

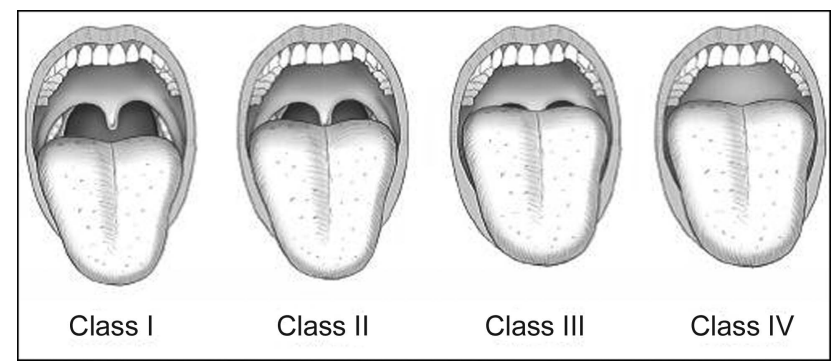

Fig. 12. Mallampati classification. From Reference 53, with permission.

lower incisors can be protruded anterior to the upper incisors; class B, the lower incisors can be brought in-line with the edge of the upper incisors but not anterior to them; and class $\mathrm{C}$, the lower incisors cannot be brought in-line with the upper incisors. Class $\mathrm{C}$ has been reported to be associated with DMV. ${ }^{49}$ The Mallampati classification system involves an examination of the patient's oral cavity. The different classifications are illustrated in Figure 12 and are described as follows: class 1, the soft palate and entire uvula are visible; class 2, the soft palate and a portion of the uvula are visible; class 3 , the soft palate is visible (the base of the uvula may or may not be visible); and class 4 , the soft palate is not visible. ${ }^{51-53}$ While the Mallampati classification system is used mainly to assess for difficult laryngoscopy, Mallampati class 4 has been associated with DMV. ${ }^{42}$

\section{Incidence of Difficult Mask Ventilation}

The incidence of DMV is reported to be quite variable in the literature. Early studies reported the incidence from $<1 \%$ to upwards of $15 \% .{ }^{54,55}$ Williamson et al ${ }^{55}$ reported the incidence of DMV as $15 \%$, but the study focused on difficult intubation, so it is hard to ascertain whether the high incidence of DMV was due to trauma and inflammation from repeated intubation attempts or other factors. The largest prospective study ( $>22,000$ patients) reported an incidence of $1.4 \% .{ }^{43}$ This study was performed in the adult population, and it is entirely possible that the incidence of DMV may be even higher in the pediatric population since there are anatomic differences. A more recent study found the incidence of DMV to be $13 \% .^{56}$ However, DMV is defined differently in each of the studies, and it ultimately becomes difficult to determine what the true incidence of DMV actually is.

\section{Summary}

Poor respiratory effort causing inadequate ventilation can be difficult to discern, as it is often silent and requires close observation of chest-wall movement. Causes of poor 
respiratory effort can be central, airway obstruction, or a foreign body. Positioning maneuvers such as the head tilt/chin lift and jaw thrust should be performed to improve air flow during basic airway management. OPA and NPA devices are important adjuncts for achieving and maintaining an open airway; however, proper insertion technique and appropriately sized devices are essential to their successful use. BMV is a crucial airway management skill but one of the most difficult to learn and perform correctly. The clinician performing BMV must carefully monitor the adequacy of technique at all times. Although not common in most care settings, DMV can nevertheless be life-threatening. It is important to identify those at risk for DMV so that appropriate measures can be taken to achieve adequate ventilation.

\section{REFERENCES}

1. Heimlich HJ. Pop goes the café coronary. Emerg Med 1974;6:154-155.

2. Heimlich HJ. A life-saving maneuver to prevent food-choking. JAMA 1975;234(4):398-401.

3. Croom DW. Rupture of the stomach after attempted Heimlich maneuver (letter). JAMA 1983;250(19):2602-2603.

4. Haynes DE, Haynes BE, Yong YV. Esophageal rupture complicating Heimlich maneuver. Am J Emerg Med 1984;2(6):507-509.

5. Meredith MJ, Liebowitz R. Rupture of the esophagus caused by the Heimlich maneuver (letter). Ann Emerg Med 1986;15(1):106-107.

6. Razaboni RM, Brathwaite CE, Dwyer WA Jr. Ruptured jejunum following the Heimlich maneuver. J Emerg Med 1986;4(2):95-98.

7. Cowan M, Bardole J, Dlesk A. Perforated stomach following the Heimlich maneuver. Am J Emerg Med 1987;5(2):121-122.

8. van der Ham AC, Lange JF. Traumatic rupture of the stomach after Heimlich maneuver. J Emerg Med 1990;8(6):713-715.

9. Bintz M, Cogbill TH. Gastric rupture after the Heimlich maneuver. Trauma 1996;40(1):159-160.

10. Fearing NM, Harrison PB. Complications of the Heimlich maneuver: case report and literature review. J Trauma 2002;53(5):978-979.

11. Agia GA, Hurst DJ. Pneumomediastinum following the Heimlich maneuver. JACEP 1979;8(11):473-475.

12. Ujjin V, Ratanasit $S$, Nagendran T. Diaphragmatic hernia as a complication of the Heimlich maneuver. Int Surg 1984;69(2):175-176.

13. Valero V. Mesenteric laceration complicating a Heimlich maneuver. Ann Emerg Med 1986;15(1):105-106.

14. Cecchetto G, Viel G, Cecchetto A, Kusstatscher S, Montisci M. Fatal splenic rupture following Heimlich maneuver: case report and literature review. Am J Forensic Med Pathol 2011;32(2):169-171.

15. Mace SE. Challanges and advances in intubation: airway evaluation and controversies with intubation. Emerg Med Clin North Am 2008; 25(4):977-1000.

16. Johnson C, Goodman NW. Time to stop sniffing the air: snapshot survey. BMJ 2006;333(7582):1295-1296.

17. Benumof JL. Comparison of intubating positions: the end point for position should be measured (letter). Anesthesiology 2002;97(3):750.

18. Adnet F, Borron SW, Lapostolle F, Lapandry C. The three axis alignment theory and the "sniffing position": perpetuation of an anatomic myth (letter)? Anesthesiology 1999;91(6):1964-1965.

19. Isono S. Common practice and concepts in anesthesia: time for reassessment: is the sniffing position a "gold standard" for laryngoscopy (editorial)? Anesthesiology 2001;95(4):825-827.

20. Adnet F, Baillard C, Borron SW, Denantes C, Lefebvre L, Galinski M, et al. Randomized study comparing the "sniffing position" with simple head extension for laryngoscopic view in elective surgery patients. Anesthesiology 2001;95(4):836-841.

21. Adnet F, Borron SW, Dumas JL, Lapostolle F, Cupa M, Lapandry C. Study of the "sniffing position" by magnetic resonance imaging. Anesthesiology 2001;94(1):83-86.

22. Donaldson WF 3rd, Heil BV, Donaldson VP, Silvaggio VJ. The effect of airway maneuvers on the unstable C1-C2 segment: A cadaver study. Spine 1997;22(11):1215-1218.

23. Schneider RE, Murphy MF. Bag/mask ventilation and endotracheal intubation. In: Walls RM, Murphy MF, editors. Manual of emergency airway management, 2nd edition. Philadelphia: Lippincott Williams \& Wilkins; 2004;43-56.

24. Bevis, R, Moore, CJ. Cardiopulmonary resuscitation. In: Hess DR, MacIntyre NR, Mishoe SC, Galvin WF, Adams AB, editors. Respiratory care: principles and practice, 2 nd edition. Sudbury, MA: Jones \& Bartlett Learning; 2012;422-423.

25. Brimacombe J, Keller C, Künzel KH, Gaber O, Boehler M, Pühringer F. Cervical spine motion during airway management: a cinefluoroscopic study of the posteriorly destabilized third cervical vertebrae in human cadavers. Anesth Analg 2000;91(5):1274-1278.

26. Sellick BA. Cricoid pressure to prevent regurgitation of stomach contents during induction of anaesthesia. Lancet 1961;2(7199):404-406.

27. Brimacombe JR, Berry AM. Cricoid pressure. Can J Anaesth 1997; 44(4):414-425.

28. Ho AH, Wong W, Ling E, Chung DC, Tay BA. Airway difficulties caused by improperly applied cricoid pressure. J Emerg Med 2001; 20(1):29-31.

29. Vanner RG, Asai T. Safe use of cricoid pressure (editorial). Anaesthesia 1999;54(1):1-3.

30. Herman NL, Carter B, Van Decar TK. Cricoid pressure: teaching the recommended level. Anesth Analg 1996;83(4):859-863.

31. Roberts K, Whalley H, Bleetman A. The nasopharyngeal airway: dispelling myths and establishing the facts. Emerg Med J 2005; 22(6):394-396.

32. Neumar RW, Otto CW, Link MS, Kronick SL, Shuster M, Callaway CW, et al. Part 8: adult advanced cardiovascular life support: 2010 American Heart Association guidelines for cardiopulmonary resuscitation and emergency cardiovascular care. Circulation. 2010;122(18 Suppl 3):S729-S767. Errata in: Circulation 2013;128(25):e480; Circulation 2011;23(6):e236.

33. Tong JL, Smith JE. Cardiovascular changes following insertion of oropharyngeal and nasopharyngeal airways. Br J Anaesth 2004;93(3): 339-342.

34. Joffe AM, Hetzel S, Liew EC. A two-handed jaw-thrust technique is superior to the one-handed "EC-clamp" technique for mask ventilation in the apneic unconscious person. Anesthesiology 2010;113(4): 873-879.

35. Davidovic L, LaCovey D, Pitetti RD. Comparison of 1- versus 2-person bag-valve-mask techniques for manikin ventilation of infants and children. Ann Emerg Med 2005;46(1):37-42.

36. Komatsu R, Kasuya Y, Yogo H, Sessler DI, Mascha E, Yang D, Ozaki M. Learning curves for bag-and-mask ventilation and orotracheal intubation. Anesthesiology 2010;112(6):1525-1531.

37. Hagberg C, Georgi R, Krier C. Complications of managing the airway. Best Pract Res Clin Anaesthesiol 2005;19(4):641-659.

38. Wenzel V, Idris AH, Banner MJ, Kubilis PS, Williams JL. The influence of tidal volume on the distribution of gas between the lungs and stomach in the unintubated patient receiving positive pressure ventilation. Crit Care Med 1998;26(2):364-368.

39. Yentis SM. Predicting trouble in airway management (editorial). Anesthesiology 2006;105(5):871-872.

40. American Society of Anesthesiologists Task Force on Management of the Difficult Airway. Practice guidelines for management of the difficult airway: an updated report by the American Society of An- 
esthesiologists Task Force on Management of the Difficult Airway. Anesthesiology 2003;98(5):1269-1277.

41. Langeron O, Masso E, Huraux C, Guggiari M, Bianchi A, Coriat P, Riou B. Prediction of difficult mask ventilation. Anesthesiology 2000; 92(5):1229-1236.

42. Yildiz TS, Solak M, Toker K. The incidence and risk factors of difficult mask ventilation. J Anesth 2005;19(1):7-11.

43. Kheterpal S, Han R, Tremper KK, Shanks A, Tait AR, O'Reilly M, Ludwig TA. Incidence and predictors of difficult and impossible mask ventilation. Anesthesiology 2006;105(5):885-891.

44. Han R, Tremper KK, Kheterpal S, O'Reilly M. Grading scale for mask ventilation (letter). Anesthesiology 2004;101(1):267.

45. Greenberg RS. Facemask, nasal and oral airway devices. Anesthesiol Clin North America 2002;20(4):833-861.

46. Murphy, MF, Walls, RM. Identification of the difficult and failed airway. In: Walls RM, Murphy MF, editors. Manual of emergency airway management, 2nd edition. Philadelphia: Lippincott Williams \& Wilkins; 2004:70-79.

47. Calder I. Predicting difficult intubation (letter). Anaesthesia 1992; 47(6):528-530.

48. Calder I, Calder J, Crockard HA. Difficult direct laryngoscopy in patients with cervical spine disease. Anaesthesia 1995;50(9):756-763.
49. Gautam TK, Gaul K, Luthra N. Prediction of difficult mask ventilation (letter). Eur Soc Anaesth 2005;22(8):638-640.

50. Davies JD, May RA, Bortner PL. Airway management. In: Hess DR, MacIntyre NR, Mishoe SC, Galvin WF, Adams AB, editors. Respiratory care: principles and practice, 2 nd edition. Sudbury, MA: Jones \& Bartlett Learning; 2012;376-418.

51. Mallampati SR. Clinical sign to predict difficult tracheal intubation (letter). Can Anaesth Soc J 1983;30(3 Pt 1):316-317.

52. Mallampati SR, Gatt SP, Gugino LD, Desai SP, Waraksa B, Freiberger D, Liu PL. A clinical sign to predict difficult tracheal intubation: a prospective study. Can Anaesth Soc J 1985;32(4):429-434.

53. Nuckton TJ, Glidden DV, Browner WS, Claman DM. Physical examination: Mallampati score as an independent predictor of obstructive sleep apnea. Sleep 2006;29(7):903-908.

54. el-Ganzouri AR, McCarthy RJ, Tuman KJ, Tanck EN, Ivankovich AD. Prospective airway assessment: predictive value of a multivariate risk index. Anesth Analg 1996;82(6):1197-1204.

55. Williamson JA, Webb RK, Szekely S, Gillies ER, Dreosti AV. Difficult intubation: an analysis of 2000 incident reports. Anaesth Intensive Care 1993;21(5):602-607.

56. Shah PN, Sundaram V. Incidence and predictors of difficult mask ventilation and intubation. J Anaesthiol Clin Pharmacol 2012;28(4): 451-455.

\section{Discussion}

Napolitano: With BMV [bag-mask ventilation], there exist both built-in PEEP valves and attachable or disposable PEEP valves. Our institution recently did not have built-in PEEP valves, and RTs [respiratory therapists] always had to go run and get one when we wanted it. So would you recommend having built-in PEEP valves for BMV or not? Would you comment on that?

Davies: I would recommend it. With BMV, although it's usually not a longterm solution, having a PEEP valve wouldn't hurt, and I think it would help in most situations. We had the same experience where RTs would have to run and get the PEEP valve if it was not included with the bag. We probably use it $10 \%$ of the time; it's usually a short gap. It becomes a cost issue, but as long as the companies throw it in, I think it's valuable to have it because you never know what type of situation you may to run into. That's a good point.

Hess: The problem I have with a PEEP valve during BMV is that, unless the mask is held completely tight, you can't maintain the PEEP. I think the PEEP valve is helpful after the patient is intubated, but during bagmask, I'm not sure the PEEP valve adds much because if there's any leak around the mask, you lose the effect of the PEEP.

Davies: But if you have the proper technique it should work!

Hess: I think even in the hands of the most skilled, for most of us, we probably have leak at least during the expiratory phase even if not during the inspiratory phase.

Davies: That's true. The other thing we've run into in the past is if a patient vomits or coughs up secretions into the valve, you can end up with a malfunctioning valve. The older valves were spring-loaded (well, I guess they still are), but the older ones tended to malfunction more often. I still think that using a properly functioning PEEP valve may help you. It's not going to hurt you.

Hess: There is some literature showing the value of using NIV [noninvasive ventilation] rather than BMV before intubation. The difference is that, with a ventilator designed specifically for NIV, there is good leak compensation, which you don't have with bagmask, so I don't think you can use that literature to support using a PEEP valve during BMV.

Ramachandran: To add to that, Dean, I think there's increased risk of gastric insufflation with the presence of a PEEP valve, so it could be dangerous in the wrong hands for mask ventilation. I want to draw attention to a study ${ }^{1}$ that came out about cricoid pressure and its effectiveness. I don't know what your experiences are with cricoid pressure, but I now rarely use 
it for my anesthesia inductions, even for emergencies. Instead, I ensure my patients are positioned with $30^{\circ}$ degree head up or reverse Trendelenburg. The study was done at McMaster University and showed that the esophagus is between the cricoid ring and the vertebral body $<50 \%$ of the time under MRI [magnetic resonance imaging] study conditions. What they showed was that cricoid pressure pushes the esophagus even farther away, in addition to potentially increasing the risk of airway obstruction. I just wanted to ask what your thoughts were about that and find out what the others' experiences were.

Davies: Our experience is that, as RTs, we're involved in a lot more emergent type of airways, and we use it not so much for BMV but for laryngoscopic view. But you're right, if cricoid pressure is used while performing BMV, without a direct view, you're not sure what's happening to the laryngeal structures.

Durbin: Another comment, the Sellick maneuver actually makes intubation more difficult. This has been demonstrated in several studies. ${ }^{2,3}$ Displacement of the larynx down and back (BURP [backwards upwards rightwards pressure)] maneuver) may help improve laryngeal view, but that's not the Sellick maneuver. I think we may be confusing 2 issues; the first is compression and occlusion of the esophagus. Even if applied correctly as advocates suggest, cricoid pressure can prevent only passive regurgitation, not active vomiting. Vomiting can actually increase with the Sellick maneuver. The second issue is using laryngeal pressure to help assist with intubation by moving the trachea or laryngeal structures into a more optimal position, which is not intended to compress the esophagus.

Blank: As a follow-up to the study you cited, I would like to mention that while the Sellick maneuver does not produce uniform and reliable compression of the esophagus, another radiographic study ${ }^{4}$ demonstrated compression of the hypopharynx and the esophageal inlet that was postulated to protect from passive reflux. It is still not clear clinically, of course, whether this maneuver actually reduces the risk of aspiration, and as you pointed out earlier, we need further studies to prove that it does improve outcomes. I agree with you that, at least from a theoretical position, a head-up position is probably more protective. In addition to the other risks of the Sellick maneuver, I just want to add that that it decreases barrier pressure reflexively, which can at least theoretically increase the risk of regurgitation and aspiration. I have to admit that when I use it with very high-risk patients, like those with achalasia, I do so with the full understanding that it may or may not improve clinical outcomes but with the hope that it will improve clinical and medicolegal outcomes.

Branson: John, I was surprised you didn't come across articles about the best method on how to squeeze the bag. Before low $\mathrm{V}_{\mathrm{T}}$ became important, some of us at this table did studies on how to get a $\mathrm{V}_{\mathrm{T}}$ of $800-1,000 \mathrm{~mL}$ during manual ventilation. I think it's important that those studies be redone now in light of the new evidence. The only thing I'll say about cricoid pressure for our readers is that at least the AHA [American Heart Association] doesn't recommend that it be used routinely. ${ }^{5}$ I'd be interested to hear what the anesthesiologists here say. The recommendation from the AHA is that if you commit to doing it, you have to maintain cricoid pressure until you intubate the patient because, as has been pointed out, releasing pressure can actually encourage regurgitation and agitation.

Davies: Yes, I did come across some of those, but didn't include them in the talk. There was a study where they measured the therapists' hands, and they marked spots on the bag where they needed to squeeze to get a suit- able $\mathrm{V}_{\mathrm{T}}$ range. They were instructed on the proper method to squeeze the bag. In this particular study, the $\mathrm{V}_{\mathrm{T}}$ produced was, for the most part, in a safe range. You're right though; there is a real danger of higher than recommended $\mathrm{V}_{\mathrm{T}}$. Some of the resuscitation bags can produce $2 \mathrm{~L}$ if completely deflated. This can become an issue during situations such as codes, where clinicians are actively resuscitating, and adrenaline has the potential to take over, leading to overactive BMV.

Hess: So should we measure tidal volume during bag ventilation?

Davies: It depends. To me, I don't think so. What we should have is a guideline with emphasis on the technique of squeezing the bag rather than actual $\mathrm{V}_{\mathrm{T}}$ measurement. In many instances, I think it would be impractical to actually measure $\mathrm{V}_{\mathrm{T}}$ due to the acuity of the situations. During a code or transport, the clinician could be responsible for helping manage several procedures at the same time, and focusing on the $\mathrm{V}_{\mathrm{T}}$ may interfere with them. I think it's important for clinicians to have a general awareness of the depth of the bag squeeze. For instance, they should know that even a halfway deflation of the bag may produce $\mathrm{V}_{\mathrm{T}}$ in the range of $750 \mathrm{~mL}$ to $1 \mathrm{~L}$.

Hess: There is accumulating evidence that the use of smaller tidal volumes may be important throughout our practice.

Davies: Yes, I agree. Again, it's short-term, and I think we need to be aware of it. I don't know that it needs to be measured.

Hurford: You mentioned training for BMV, and this is a good point. How do you train someone to give the right airway pressure and $\mathrm{V}_{\mathrm{T}}$ ? We do that at our ACLS [advanced cardiovascular life support] training for all our clinicians who give sedative drugs. Everybody who goes through ACLS 
goes through a bag mask simulator that is incredibly frustrating. Even for myself. "Your $\mathrm{V}_{\mathrm{T}}$ is too large. Your $\mathrm{V}_{\mathrm{T}}$ is too small. Ventilate slower." It's fascinating to get this feedback, and it's also a good way of verifying that yes, this person knows how to do BMV. This person knows to limit $\mathrm{V}_{\mathrm{T}}$. I think incorporating that into ACLS training that you have to do every 2 years anyway is probably a good way of maintaining competency or verifying competency of BMV.

Davies: I agree with you. I also think that, in our practice as RTs, it should be part of our annual competencies, with more emphasis on proper technique and guidance on what kind of volumes are being produced.

Durbin: I agree; I don't think even our residents learn how to manage airways using just their hands and a mask. I don't think our young RTs know how to optimally perform mask ventilation because they do so little of it during training. With the availability of all the new airway adjuncts and intubation techniques, it is no longer very sexy to manage airways without them. The only way to become an expert in airway management is to do a lot of it. I don't think the current generation or even the recent past generations left their training programs with enough airway management experience or skill. This is simply because we have too many other useful ways to manage upper airways.

Blank: In response to Dr Durbin's comment, I don't include myself in the recent generation, and having come from the generation who trained under Dr Durbin, I was required to perform 2-3-h cases with mask ventilation.

Durbin: Two to 3-h cases? How about for $12 \mathrm{~h}$ ?

\section{REFERENCES}

1. Smith KJ, Dobranowski J, Yip G, Dauphin A, Choi PT. Cricoid pressure displaces the esophagus: an observational study using magnetic resonance imaging. Anesthesiology 2003;99(1):60-64.

2. Haslam N, Parker L, Duggan JE. Effect of cricoid pressure on the view at laryngoscopy. Anaesthesia 2005;60(1):41-47.

3. Harris T, Ellis DY, Foster L, Lockey D. Cricoid pressure and laryngeal manipulation in 402 pre-hospital emergency anaesthetics: essential safety measure or a hindrance to rapid safe intubation? Resuscitation 2010;81(7):810-816.

4. Rice MJ, Mancuso AA, Gibbs C, Morey TE, Gravenstein N, Deitte LA. Cricoid pressure results in compression of the postcricoid hypopharynx: the esophageal position is irrelevant. Anesth Analg 2009;109(5): 1546-1552.

5. Field JM, Hazinski MF, Sayre MR, Chameides L, Schexnayder SM, Hamphill R, et al. Part 1: executive summary: 2010 American Heart Association Guidelines for Cardiopulmonary Resuscitation and Emergency Cardiovascular Care. Circulation 2010;122(18 Suppl 3):S640-S656.

This article is approved for Continuing Respiratory Care Education credit. For information and to obtain your CRCE

(free to AARC members) visit

www.rcjournal.com

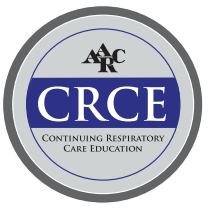

